\title{
Antidiabetic and Antihyperlipidemic Effects of Aqueous Extract of Carica papaya Leaf on the Experimental Model against Single Alloxan Toxicity
}

\author{
Ukpabi C.F. ${ }^{1}$ \\ Chukwu M.N ${ }^{2 \rtimes}$ (D) \\ Onyemaechi, J.N. ${ }^{3}$ \\ Ibe $\mathbf{P}^{4}$ (iD \\ Onuh E.F. ${ }^{5}$
}

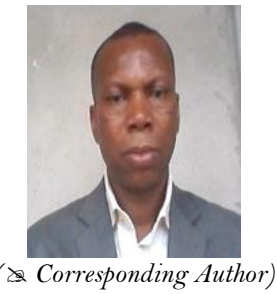

'Department of Biochemistry, Abia State Polytechnic, Aba, Nigeria 'Email:ukpabichibueze@yahoo.com Tel: +2348062667790

¿Department of Biochemistry and Department of Food Technology Abia State Polytechnic, Aba, Nigeria 'Email:mchukwu61@gmail.com Tel.+2348184516106

${ }_{3,4,5}$ Department of Chemistry, Abia State Polytechnic, Aba, Nigeria

${ }^{5}$ Email:prettyjoyngozi@gmail.com Tel: +23480120540509

${ }^{4}$ Email:peekayibe68@gmail.com Tel: +2347066822469

Email. alphamelomusomailcom Tel. +2848089861875

Abstract

Antidiabetic and antihyperlipidemic effects of aqueous extract of Carica papaya leaf on the toxicity were investigated. A total of thirty rats were divided into six groups of 5 rats: Group A: Normal control, Group B: Negative control, Group C: Positive control I, Group D: Positive control II, Group E: Test control I, Group F: Test control II. Diabetes was induced with a single dose of alloxan $(120 \mathrm{mg} / \mathrm{kg})$ body weight and serum glucose was taken $72 \mathrm{hrs}$ after induction to confirm diabetes. The oral administration for hyperglycemia and hyperlipidemia started on the $4^{\text {th }}$ and $8^{\text {th }}$ day of the experiment respectively. The result showed that Carica papaya leaf extract significantly and progressively lowered the glucose level, TG, TC and LDL dose dependently while significantly causing a dose-related elevation in HDL concentration when compared to the untreated control and positive control groups (I \& II) treated rats. Phytochemical analysis revealed the presence of alkaloids, flavonoids, saponins and tannins. The aqueous extract of this plant can be used to brew a tonic that will allay the metabolic disruption produced by diabetes.

Keywords: Carica papaya, Phytochemicals, Antidiabetic, hyperlipidemia activities, Lipoproteins, hyperglycermia

Citation | Ukpabi C.F.; Chukwu M.N.; Onyemaechi, J.N.; Ibe P.; Onuh E.F. (2019). Antidiabetic and Antihyperlipidemic Effects of Aqueous Extract of Carica papaya Leaf on the Experimental Model against Single Alloxan Toxicity. World Scientific Research, 6(1): 1418

\section{History:}

Received: 13 March 2019

Revised: 17 April 2019

Accepted: 22 May 2019

Publisted: 21 July 2019

Licensed: This work is licensed under a Creative Commons

Attribution 3.0 License (c)

Publisher: Asian Online Journal Publishing Group
Acknowledgement: All authors contributed to the conception and design of the study.

Funding: This study received no specific financial support

Competing Interests: The authors declare that they have no conflict of interests.

Transparency: The authors confirm that the manuscript is an honest, accurate, and transparent account of the study was reported; that no vital features of the study have been omitted; and that any discrepancies from the study as planned have been explained.

Ethical: This study follows all ethical practices during writing.

\section{Contents}

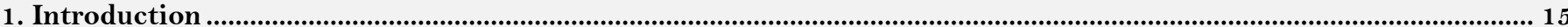

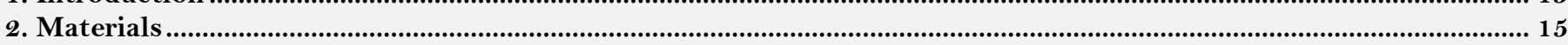

3. Methodology

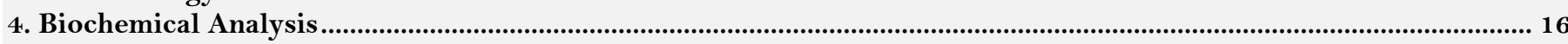

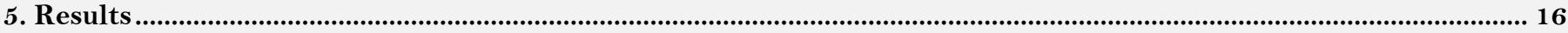

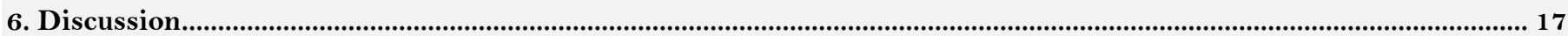

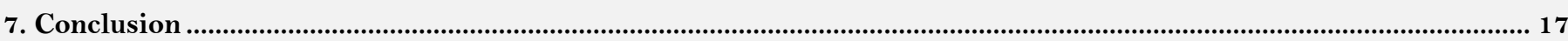

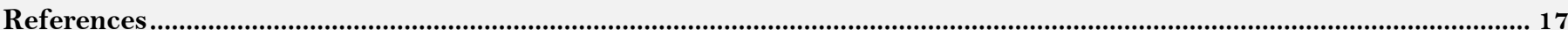




\section{Contribution of this paper to the literature}

In this study, it has been demonstrated that diabetes mellitus induced by alloxan administration in albino rats cultivated hyperlipidemia. Subsequently, the hyperlipidemia was normalized by the administration of the leaf extract of Carica papaya.

\section{Introduction}

Diabetes mellitus is one of the fastest growing long term diseases that affects millions of people worldwide. It is a metabolic disorder of multiple etiologies characterized by chronic hyperglycemia with disturbance of carbohydrate fat and protein metabolism (1). This is either as a result of defects in insulin secretion or insulin action/ both. Chronic hyperglycemia is the hallmark of this disease. Diabetes mellitus is rapidly emerging as a major public health problem in Nigeria. The prevalence rate of Type II diabetes according to the W.H.O., was estimated to be over $3.4 \%$ of 24 million Nigerians between the ages of $20-79$ years and with projected estimate of $3.9 \%$ rise in $2025[1,2]$. The most important diabetic complication is dyslipidemia. This is characterized by predominance of elevated triglycerides, total cholesterol, low density lipoprotein (LDL) and decrease in high density lipoprotein (HDL). These lipid abnormalities may be due to the rise in cholesterylester hydrolase and reduction in activation of lipoprotein lipase [3].

Alloxan induced diabetes in one of the widely used model to induce type I diabetes mellitus in the experimental animals. Alloxan has been found to be selectively toxic to pancreatic beta cells. In poorly controlled type I and II diabetes,dyslipidemia commonly occurs and it is believed to be mediating step in cardiovascular disease [4].

Despite the existing pharmacotherapy, it is still difficult to attain adequate glycemic control amongst many diabetes patients due to the progressive decline in beta cell function of the pancreas and other vital organs in the body [5]. In Nigeria polytherapy with two or more of hypoglycemic agents to achieve better glucose control is common practice. In spite of this, there is also a high incidence of diabetic complications and hyperglycemic emergencies. As a result, patients often have resource to alternative forms of therapy such as herbal plants.

Several herbs have been investigated to ameliorate abnormalities in lipid metabolism arising from diabetes metabolic disorder in many institutions located in different regions of the world. One of the medical plants widely used in traditional treatment system is the Carica payaya leaf which belongs to the family Caricaceae. In line with the increasing importance of traditional medicine in various healthcare systems around the world the WHO traditional medicine strategy has recently been updated. The goals of the strategy for the last decade are to support member states in harnessing the potential contribution of traditional medicine to health and wellness as well as promoting the safe and effective use of traditional medicine by regulating, researching and integrating traditional medicine products, practitioners and practice into health systems where appropriate [6]. This has necessitated exploration and screening of medicinal plants with acclaimed therapeutic efficacies in diabetes mellitus management. Therefore, the objective of this research is to investigate the hypoglycemic effect of Carica papaya leaf on the laboratory induced rats and it's potential to ameliorate diabetic hyperlipidemia. In doing so, we will attain to provide the pharmacological evidence for their therapeutic usage.

\section{Materials}

1. Materials/Apparatus: Fresh leaves of Carica papaya, 30 albino rats, glass bottles, ASTM 60mesh, water bath, weighing balance, micro pipettes, Centrifuge, desiccator, Accu-chek Glucometer, thermometer, cages for rats, spectrophotometer.

2. Chemicals/Reagents utilized: Alloxan monohydrate (Qualikems, India.), Atorvastatin (Unipex, USA.), cholesterol reagents (Teco diagnostics USA) Triglyceride GPO reagents (Teco Diagnostics, USA) and HDL cholesterol reagents (Agape diagnostics Switzerland) were obtained from various distribution companies in Abia State.

3. Plant Sample Collection: Fresh Carica papaya leaves (Paw-paw leaf) were collected in February, 2018 from Abam-Ubakala Umuahia South Local Government Area, Abia State Nigeria. The leaves were authenticated by Dr. Ndukwe, Okorie of the Department of Biology of Abia State Polytechnic Aba, Abia State.

4. Experimental Animals: Young adult Wister rats weighing between $130 \mathrm{~g}$ and $160 \mathrm{~g}$ were used for this study. The rats were obtained from Department of Zoology, University of Nigeria, Nsukka (UNN), Enugu State and kept in the animal house of the Department of Biology, Abia State Polytechnic Aba, Abia State. The rats were allowed one week of acclimatization at temperature of $28^{\circ} \mathrm{C}$ under $12 \mathrm{hr}$ light dark cycle with free access to animal feed and water.

\section{Methodology}

Plant Sample Preparation: The leaves of the plant were thoroughly washed with clean water and air dried. The dried sample was pulverished using electric grinder. The powdered sample was stored in a clean dried bottled container.

Preparation of plant Aqueous Extract: The powdered sample (50g) was soaked in $400 \mathrm{ml}$ of hot distilled water $\left(50^{\circ} \mathrm{C}-70^{\circ} \mathrm{C}\right)$ for 6 hours after which it was filtered using a piece of white cotton gauze. The process was repeated each day throughout the period of the experiment.

Phytochemical analysis of the sample: The aqueous extract was subjected to various qualitative tests for identification of the phytochemical constituents which includes; Alkaloids, Saponins, Flavonoids, Tannins using the various methods adopted by Ukpabi, et al. [7].

Induction of diabetes mellitus: Experimentally, diabetes was induced on the acclimatized albino rats via a single intraperitoneal injection of alloxan monohydrate $(120 \mathrm{mg} / \mathrm{kg})$ after an overnight fast. After 72 hours of alloxan injection, blood samples were collected to determine the blood glucose concentration to confirm the development of diabetes mellitus. Rats with fasting blood sugar (glucose) concentrations of greater than $\geq$ $250 \mathrm{mg} / \mathrm{dl}$ were considered hyperglycemic and selected for the study [8]. 
Experimental design and treatment: The animals were randomly divided into six (6) groups each containing five (5) rats in various animal cages.. Group A received a red mark on the cage while Group B received a blue mark as well as Group C green mark. Group D E and F cages were marked with black, brown and white colours respectively. Subsequently, treatment regimes of hyperglycemia and hyperlipidemia started on the $4^{\text {th }}$ and $8^{\text {th }}$ day of the experiment respectively

Group A: (Normal control) - The rats in this group were allowed free access to animal feed and water. They were not intoxicated and hence, not treated.

Group B: (Negative control) - The rats in this group were induced with single intraperitoneal (Ip) injections of alloxan $(120 \mathrm{mg} / \mathrm{kg})$ and were not given any form of treatment.

Group C: (Positive control 1) - The rats in this group were induced with alloxan monohydrate $(120 \mathrm{mg} / \mathrm{kg}$ ) intraperitoneally and treated with insulin $(40 \mathrm{mg} / \mathrm{kg})$ as a reference drug for diabetic study.

Group D: (Positively control II) - The rats in this group were induced with alloxan monohydrate $(120 \mathrm{mg} / \mathrm{kg}$ ) intraperitoneally and treated with atorvastatin $(30 \mathrm{mg} / \mathrm{kg})$ as a reference drug for lipid study.

Group E: (Test control 1) - The rats in this group were administered with aqueous extract of Carica papaya as low dose $(200 \mathrm{mg} / \mathrm{kg} / \mathrm{ml} /$ day $)$ after single alloxan monohydrate $(120 \mathrm{mg} / \mathrm{kg})$ intraperitoneal induction.

Group F: (Test control II) - The rats in this group were administered with aqueous extract of Carica papaya $(1 \mathrm{ml} /$ day $)$ as high dose $(400 \mathrm{mg} / \mathrm{kg} / \mathrm{ml} /$ day $)$ after alloxan monohydrate $(120 \mathrm{mg} / \mathrm{kg})$ intraperitonal induction.

\section{Biochemical Analysis}

\subsection{Lipid Profile Assay}

Blood samples were collected from the animals and serum portions separated and immediately biochemical determinations were performed. Serum levels of cholesterol (TC), triglycerides (TG), High-density lipoproteincholesterol (HDL-C) and low-density lipoprotein-cholesterol (LDL-C) were analyzed using enzymatic method kits from Teco Diagnostics.

\subsection{Glucose Estimation}

Glucose determination were carried out using the glucose oxidase method as presented by the Biosystems glucose test kit

GLUCOSE $+1 / 2 \mathrm{O}_{2}+\mathrm{H}_{2} \mathrm{O} \stackrel{\text { Glucose Oxidase }}{\longrightarrow}$ Gluconate $+\mathrm{H}_{2} \mathrm{O}_{2}$

$2 \mathrm{H}_{2} \mathrm{O}_{2}+4$ - Aminoantipyrene + phenol $\stackrel{\text { Peroxidase }}{\longrightarrow}$ Quinoneimine $+4 \mathrm{H}_{2} \mathrm{O}$

The reaction complex was measured spectrophotometrically.

\section{Results}

\subsection{Phytochemical Composition of Aqueous Leaf Extract of Carica papaya}

Result obtained Table 1 showed that the aqueous extract of the dried powder of Carica papaya leaf gave positive reactions for alkaloids, Flavonoids, Saponins and Tannins. Alkaloids reaction gave the deepest colouration followed by flavonoids and Saponins and then tannins.

Table-1. Qualitative Phytochemical constituents of Aqueous extract of Carica papaya leaf.

\begin{tabular}{c|c|c}
\hline S/N & Phytochemical constituents & Qualitative Abundance \\
\hline 1. & Flavonoids & ++ \\
\hline 2. & Alkaloids & +++ \\
\hline 3. & Saponins & ++ \\
\hline 4. & Tannins \\
\hline$+=$ Weakly Present & & + \\
+++ & Moderately present \\
++ & Strongly Present.
\end{tabular}

5.2. Serum Glucose Concentrations of Alloxan Induced Albino Rats Following Oral Administration of Aqueous Leaf Extracts of Carica Papaya

Results obtained from the diabetic study Table 2 on albino rats with $130-160 \mathrm{~g}$ body weight showed that the aqueous leaf extract of Carica papaya decreased blood glucose in a dose dependent fashion. Decrease in the blood glucose concentrations was significant when compared to the diabetic control.

Table-2. Effect of Aqueous leaf extracts of Carica papaya on Blood Glucose concentrations of alloxan induced albino rats.

\begin{tabular}{c|c|c|c|c}
\hline Groups & $\begin{array}{c}\text { Initial glucose } \\
\text { concentration } \\
(\mathbf{m g} / \mathbf{d l})\end{array}$ & $\begin{array}{c}\text { Glucose concentration } \\
\text { after 4days of treatment } \\
(\mathbf{m g} / \mathbf{d l})\end{array}$ & $\begin{array}{c}\text { Glucose concentration } \\
\text { after 8days of treatment } \\
(\mathbf{m g} / \mathbf{d l})\end{array}$ & $\begin{array}{c}\text { Glucose concentration } \\
\text { after } \mathbf{1 2 d a y s ~ o f ~} \\
\text { treatment }\end{array}$ \\
\hline Group A & $83.00 \pm 2.30$ & $83.40 \pm 3.20$ & $84.00 \pm 1.98$ & $85.50 \pm 2.91$ \\
\hline Group B & $283.00 \pm 1.34$ & $268.36 \pm 1.64$ & $257.25 \pm 1.12$ & $243.13 \pm 1.05$ \\
\hline Group C & $280.00 \pm 1.34$ & $180.25 \pm 2.96$ & $110.12 \pm 1.33$ & $97.13 \pm 1.91$ \\
\hline Group E & $285.00 \pm 3.33$ & $216.50 \pm 2.67$ & $150.00 \pm 1.59$ & $105.00 \pm 1.51$ \\
\hline Group F & $275.00 \pm 2.57$ & $205.6 \pm 2.84$ & $140.00 \pm 2.03$ & $85.00 \pm 4.56$ \\
\hline Source: Experimental Data & & & \\
\hline
\end{tabular}

Source: Experimental Data.

\subsection{Effect of Alloxan-Monohydrate Induction on Lipid Profile of Albino Rats}

Intoxication of albino rats with alloxan-monohydrate produced elevated lipid profile values of TG, TC, and LDL which were significantly higher than the normal control while HDL which was significantly decreased. 
Table-3. Serum lipid levels in albino rats following the induction of alloxan monohydrate $(120 \mathrm{mg} / \mathrm{kg})$.

\begin{tabular}{c|c|c|c|c}
\hline Group & Total Cholesterol $(\mathbf{m g} / \mathbf{d l})$ & Triglyceride $(\mathbf{m g} / \mathbf{d l})$ & HDL $(\mathbf{m g} / \mathbf{d l})$ & $\mathbf{L D L}(\mathbf{m g} / \mathbf{d l})$ \\
\hline Group A & $80.51 \pm 1.34$ & $81.87 \pm 1.91$ & $38.64 \pm 2.96$ & $28.82 \pm 1.33$ \\
\hline Group B & $149.89 \pm 3.33$ & $159.21 \pm 1.51$ & $23.53 \pm 1.59$ & $53.19 \pm 2.67$ \\
\hline
\end{tabular}

\subsection{Effect of the Aqueous Extracts of Carica Papaya Leaf of the Serum Lipid Profile on Diabetic Rats}

Results obtained in Table 3 showed that serum TG, TC and LDL concentrations in alloxan intoxicated animals were decreased towards the normal. Treatment with the extract also increased the HDL concentrations towards the normal. The responses were in dose dependent manner.

Table-4. Effect of Atorvastatin and aqueous leaf extracts treatment of Carica papaya on Diabetic albino rats.

\begin{tabular}{c|c|c|c|c|c|c|c|c}
\hline Group & \multicolumn{2}{|c|}{$\begin{array}{c}\text { Total cholesterol } \\
(\mathbf{m g} / \mathbf{d l})\end{array}$} & \multicolumn{2}{c|}{$\begin{array}{c}\text { Total triglyceride } \\
(\mathbf{m g} / \mathbf{d l})\end{array}$} & \multicolumn{2}{c|}{$\begin{array}{c}\text { High } \\
\text { density } \\
\text { lipoprotein(mg/dl) }\end{array}$} & $\begin{array}{c}\text { Low density } \\
\text { lipoprotein (mg/dl) }\end{array}$ \\
\hline & 13 days & 18 days & 13 days & 18 days & 13 days & 18 days & 13 days & $18 \mathrm{days}$ \\
\hline $\mathrm{D}$ & $119.88 \pm 3.12$ & $86.29 \pm 2.57$ & $121.77 \pm 3.38$ & $84.63 \pm 2.84$ & $28.99 \pm 3.38$ & $37.48 \pm 4.56$ & $46.60 \pm 0.95$ & $29.40 \pm 2.03$ \\
\hline $\mathrm{E}$ & $138.74 \pm 4.15$ & $131.55 \pm 3.85$ & $149.20 \pm 4.70$ & $140.84 \pm 5.70$ & $26.75 \pm 1.21$ & $31.64 \pm 2.21$ & $52.10 \pm 2.55$ & $47.85 \pm 1.41$ \\
\hline $\mathrm{F}$ & $117.70 \pm 5.80$ & $98.50 \pm 4.25$ & $107.10 \pm 4.26$ & $97.21 \pm 3.75$ & $32.74 \pm 3.51$ & $36.01 \pm 4.51$ & $49.44 \pm 2.15$ & $44.01 \pm 2.37$ \\
\hline \multicolumn{7}{l}{ Source: Experimental Data. }
\end{tabular}

\section{Discussion}

Evidence from the reviewed literature showed that the phytochemical compounds have the potentials to stimulate the immune system, prevent toxic substances in the diet from becoming carcinogenic reduce inflammation, prevent DNA damage and aid DNA repair, reduce oxidative damage to cells to self-destruction (apoptosis) before they can reproduce, help regulate intracellular signaling of hormones and gene expression and activate insulin receptors. These chemical compounds produced by plants generally help them thrive or thwart competitors, predators or pathogens. Phytochemicals exhibit a wide range or biological effects as consequences of their antioxidant properties [8]. Traditional herbal tonics are supplements which serve as the main source of antioxidants for ancient people that protected them from the damage caused by free radicals.

The potential antioxidant effect of medicinal plants is of great importance because there exists convincing evidence that oxidative stress and reactive oxygen species (ROS) play an important role in the etiopathogenesis and/or progression of a number by human disease. This may occur when the generation of reactive oxygen species in a system exceeds the system's ability to neutralize and eliminate them.

Alloxan (2, 4, 5, 6-tetraoxypyrimidine) is an oxygenated pyrimidine derivative which is present as alloxan hydrate in aqueous solution. One of the mechanisms that has been reported is the effect of ROS on the DNA of pancreatic islets [9]. The fragmentation of DNA takes place in the beta cells exposed to alloxan that causes DNA damage. Another mechanism is the disturbance in intracellular calcium homesotatis which has also been reported to constitute an important step in the diabetogenic action of alloxan [8]. It has been noted that alloxan elevates cytosilic free $\mathrm{Ca}^{2+}$ concentration in the beta cells of pancreatic islets [9].

In the present study, rats treated with single dose of alloxan monohydrate developed pancreatic damage which was observed from a substantial increase in blood glucose levels. The use of lower dose alloxan $(120 \mathrm{mg} / \mathrm{kg})$ produced partial destruction of pancreatic beta cells even though the animals have surviving beta cells and regeneration is possible [10]. The present data indicated that the aqueous of Carica payaya significantly reduced the elevated blood glucose levels in a dose-dependent, manner. Another observation arising from this study is the sharp pattern of glucose concentration decrease in the $3^{\text {rd }}$ day of the insulin treatment assay when compared with the plant extracts.

However, the plant extracts efficiency was significant when compared to the reference drug (insulin). The intoxication showed rise in blood glucose which was accompanied by marked increase in total cholesterol (TC) triglyceride (TG), Low density lipoprotein (LDL) and a reduction in high density lipoprotein (HDL) which is a characteristics feature of uncontrolled diabetes Table 3. Treatment with the extracts increased the HDL concentrations and decreased the LDL, TC and TG concentrations in alloxan intoxicated animals towards the normal in a dose dependent manner. The reference drug Atrovastatin was most effective in TG and TC reduction whereas high dose aqueous extract of Carica papaya leaf was most effective in LDL and HDL moderation. The results of the phytochemical analysis of the aqueous leaf extract of Carica papaya showed the presence of alkaloids, flavonoids, saponins and tannins. Previous studies have reported some of these phyto components to elicit a wide range of biological activities [11].

\section{Conclusion}

This preliminary study confirms the hypoglycemic effect of Carica papaya leaves together with the hypolipidemic benefits in diabetic rats. The aqueous extract of this plant can be used to brew tonic that will allay the metabolic disruption produced by diabetes. This plant extract can therefore be used not only to control glucose homeostasis in diabetes but to control dyslipidemia as well.

\section{References}

[1] Word Health Organization, World health statistics indicator. Geneva: WHO Press, 2011

[2] J. L. Tsnum, "Antihyperipidemic effect of SoIanum incanum on Alloxan induced diabetic wistar Albino Rats," Cardiovascular Pharmacology: Open Access, vol. 7, pp. 230-239, 2018.

[3] C. Ukpabi, J. Nwankwo, T. Esihe, and J. Isu, "Effect of aqueous leaf extract of Vernonia Amygdalina on blood glucose and lipid profile of alloxan diabetic rats," Journal of Pharmacy and Biological Sciences, vol. 13, pp. 13-17, 2018.

[4] I. Goldberg, "Diabetic dysipidemia: Causes and consequences," The Journal of Clinical Endocrinology and Metabolism, vol. 86, pp. 965-971, 2001. Available at: https://doi.org/10.1210/jc.86.3.965. 
[5] G. Graziani, G. D’argenio, C. Tuccillo, C. Loguercio, A. Ritieni, F. Morisco, C. D. V. Blanco, V. Fogliano, and M. Romano, "Apple polyphenol extracts prevent damage to human gastric epithelial cells in vitro and to rat gastric mucosa in vivo," Gut, vol. 54, pp. 193-200, 2005. Available at: https://doi.org/10.1136/gut.2004.046292.

[6] World Health Organization, WHO launches the first global strategy on traditional and alternative medicine. vol. 38: WHO Press Release, 2002.

[7] C. Ukpabi, K. F. Agbafor, O. N. Ndukwe, A. K. Agwu, and S. N. Nwachukwu, "Phytochemical of composition of coutus aftervextract and its alleviation of carbon tetrachloride-induced Hepatic oxidative stress and toxicity," International Journal of Modern Botany, vol. 2, pp. 120-126, 2012. Available at: https://doi.org/10.5923/j.ijmb.20120205.01. [8] B. Iranloye, A. Arikawe, G. Rotimi, and A. Sogbade, "Anti-diabetic and anti-oxidant effects of Zingiber Officinale on alloxan-

[9] K.-G. Lee, T. Shibamoto, G. R. Takeoka, S.-E. Lee, J.-H. Kim, and B.-S. Park, "Inhibitory effects of plant-derived flavonoids and phenolic acids on malonaldehyde formation from ethyl arachidonate," Journal of Agricultural and Food Chemistry, vol. 51, pp. 72037207, 2003. Available at: https://doi.org/10.1021/jfo345447.

[10] H. N. Ginsberg, "Diabetic dyslipidemia: Basic mechanisms underlying the common hypertriglyceridemia and low HDL cholesterol levels," Diabetes, vol. 45, pp. S27-S30, 1996. Available at: https://doi.org/10.2337/diab.45.3.s27.

[11] A. Adeneye and J. Olagunju, "Preliminary hypoglycemic and hypolipidemic activities of the aqueous seed extract of Carica papaya Linn in Wistar rats," Biology and Medicine, vol. 1, pp. 1-10, 2009. 